\title{
The effect of intravenous labetalol administration on hemodynamic responses during desflurane inhalation
}

\author{
Hyun-Seok Do, Sae Yeon Kim, Su-Jeong Heo, and Sang-Jin Park \\ Department of Anesthesiology and Pain Medicine, College of Medicine, Yeungnam University, Daegu, Korea
}

Background: Inspired concentrations of desflurane $\geq 1$ minimum alveolar anesthetic concentration (MAC) have been related to sympathetic stimulation such as hypertension and tachycardia. The current study examined whether labetalol, an $\alpha_{1}$ and $\beta$-adrenergic antagonist would blunt these hemodynamic responses.

Methods: Fifty-four ASA physical status I patients, aged 20-60 years, were enrolled in this study. The patients were randomly divided into 2 groups. The breathing circuit was primed with an end-tidal desflurane concentration of 1.2 MAC in $6 \mathrm{~L} / \mathrm{min} \mathrm{O}_{2}$. Normal saline $5 \mathrm{ml}$ or labetalol $0.3 \mathrm{mg} / \mathrm{kg}$ was injected into groups $\mathrm{S}$ and L respectively. After 5 minutes, anesthesia was induced with intravenous etomidate $0.2 \mathrm{mg} / \mathrm{kg}$ and vecuronium $0.1 \mathrm{mg} / \mathrm{kg}$. Each patient inhaled desflurane through a tight fitting facemask. Heart rate (HR), systolic blood pressure (SBP), diastolic blood pressure (DBP), mean arterial pressure (MAP) and end-tidal concentration of desflurane (et-des) were measured at 5 minutes after saline or labetalol injection (baseline) and every 1 minute for 5 minutes after desflurane inhalation and for 2 minutes after intubation.

Results: In the saline injection group (group S), desflurane inhalation increased heart rate and blood pressure, while labetalol $0.3 \mathrm{mg} / \mathrm{kg}$ attenuated the heart rate and blood pressure increase in group L. After tracheal intubation, heart rate and blood pressure were significantly lower in group $\mathrm{L}$ than in group $\mathrm{S}$.

Conclusions: These results demonstrate that administration of intravenous labetalol is effective in attenuating tracheal intubation and desflurane-induced hemodynamic responses. (Korean J Anesthesiol 2012; 62: 245-250)

Key Words: Desflurane, Hypertension, Labetalol, Tachycardia.

\footnotetext{
Received: March 17, 2011. Revised: 1st, May 11, 2011; 2nd, July 1, 2011; 3rd, July 11, 2011. Accepted: July 15, 2011.

Corresponding author: Sang-Jin Park, M.D., Department of Anesthesiology and Pain Medicine, College of Medicine, Yeungnam University, 317-1, Daemyung-dong, Nam-gu, Daegu 705-717, Korea. Tel: 82-53-620-3366, Fax: 82-53-626-5275, E-mail: apsj0718@naver.com

(ㄷ) This is an open-access article distributed under the terms of the Creative Commons Attribution Non-Commercial License (http:// creativecommons.org/licenses/by-nc/3.0/), which permits unrestricted non-commercial use, distribution, and reproduction in any medium, provided the original work is properly cited.
} 


\section{Introduction}

Desflurane is useful for rapid induction and recovery from anesthesia because of its lower coefficients of blood solubility when compared to other volatile anesthetics. However, a rapid increase of desflurane concentration to value $\geq 1$ minimum alveolar concentration (MAC) can cause hypertension and tachycardia by sympathetic activation [1]. It can also intensify cardiovascular activity during induction of general anesthesia due to hemodynamic changes of endotracheal intubation. This could be a serious complication leading to myocardial ischemia in a patient suffering from cardiovascular disease [2]. Therefore, a variety of methods have been investigated to control a sympathetic stimulation by desflurane [1,3,4]. Opioids can be only used clinically and esmolol, a $\beta$-adrenergic receptor blocker, attenuated the heart rate response but no other response [1]. By comparison, labetalol, a combined blocker of $\alpha_{1}, \beta$-receptor, reaches its peak effect at 5 to 15 minutes after intravenous injection and rapidly redistributes (5.9 minutes redistribution half-life) [5]. Therefore, it is possible that labetalol can attenuate tachycardia and hypertension by an inhalation of desflurane when inducing anesthesia. However, there have been no studies concerning the effect of labetalol on desflurane inhalation. The aim of this study was to determine the blunting effects of labetalol on desflurane-induced hemodynamic responses during induction of general anesthesia.

\section{Materials and Methods}

After approval by the clinical research committees, 54 American Society of Anesthesiologists physical status I patients between 20-60 years old submitted their written informed consent to be included in this study. The patients were scheduled for operations for treatment of stomach cancer, large intestine cancer, uterine cancer, ovarian cancer, or middle ear infection (myringoplasty and tympanoplasty). The patients with cardiovascular, respiratory or central nervous system disease, a difficulty in maintaining their airway upon induction of anesthesia, and subject with a blood pressure $\geq 140 / 90 \mathrm{mmHg}$ after arriving for operation and then resting for 10 minutes were excluded from the study. Patients with bradycardia (HR $<45$ beats/min), or severe hypotension on inducing anesthesia (decreasing BP $>30 \%$ rather than mean arterial pressure just before labetalol/saline injection or systolic pressure $<80$ $\mathrm{mmHg}$ ) were excluded from the study and an endotracheal intubation was performed after adequate treatment. The patients were randomly divided one of 2 groups (group $S$ and group L). Group S (control group) was injected with $5 \mathrm{ml}$ of normal saline and group L (experimental group) was injected 5 $\mathrm{ml}$ of labetalol $(0.3 \mathrm{mg} / \mathrm{kg})$.

We entered patient data (age, height and weight) into the anesthesia monitor equipped with a multi gas analyzer $\left(\mathrm{S} / 5^{\mathrm{TM}}\right.$ Compact anesthesia monitor, GE healthcare, Finland). The breathing circuit was earlier primed with 1.2 MAC desflurane in $\mathrm{O}_{2} 6 \mathrm{~L} / \mathrm{min}$. The gas collection tube was attached between a Y-furcation and a facial mask to check end tidal desflurane concentration. We did not performed premedication. Patients were monitored HR, pulse-oximetry, capnography, BP and end-tidal desflurane concentration. Patients were injected with labetalol or saline. Five minutes later, we injected etomidate $(0.2$ $\mathrm{mg} / \mathrm{kg})$ and vecuronium $(0.1 \mathrm{mg} / \mathrm{kg})$ for induction of anesthesia. A research assistant attached a facial mask connecting an anesthesia circuit filled with desflurane on the face of the patient to minimize any leakage and ventilated with a tidal volume $10 \mathrm{ml} / \mathrm{kg}$, respiratory rate $10 / \mathrm{min}$ after confirming loss of consciousness. Intubation was attempted 5 minutes after the start of desflurane inhalation. HR, BP and end tidal desflurane concentration were recorded at labetalol or saline pre-injection, just before desflurane inhalation ( 5 minutes after labetalol or saline injection, baseline), every minute for 5 minutes after desflurane inhalation, immediately and 2 minutes after intubation. Side effects observed during the study included severe hypertension (increasing systolic $\mathrm{BP} \geq 180 \mathrm{mmHg}$ ) and tachycardia ( $\mathrm{HR} \geq 130$ beats/min) and were recorded before and after endotracheal intubation. Other side effects including serious hypotension, arrhythmia, laryngeal, and bronchial spasm were recorded prior to the operation.

Twenty-three patients were required in each group to detect a difference of mean arterial pressure between group $\mathrm{L}$ and group S, with the standard deviation (SD) $8.62 \mathrm{mmHg}$ for $95 \%$ power and an $\alpha$ value of 0.05 . The sample size of 27 patients in each group was determined considering a $10 \%$ failure rate for data collection. Results were analyzed by SPSS (version 18.0, SPSS Inc., USA) and the data was expressed as the mean \pm SD or the number of patients. The comparison of age, height, and weight were done using the independent t-test, and the gender and occurrence of side-effects was compared by a Chisquare test. The changes of hemodynamic data and end tidal desflurane concentration in each group were analyzed by repeated ANOVA. The comparisons of blood pressure, heart rate and end tidal desflurane concentration between group $\mathrm{S}$ and group L were performed as follows. The differences between baseline and hourly measurements were calculated in each group and then it was determined whether these variations at each measurement time showed significant difference between the each group by using an independent t-test. A $\mathrm{P}$ value $<0.05$ was considered statistically significant. 


\section{Results}

There were no differences between group S and group L in the gender, age, weight, and height (Table 1). The hemodynamic data just before labetalol or saline injection also were not significantly different between the groups (Fig. 1 and 2). Within 5 minutes after labetalol injection (just before desflurane, baseline), HR (group S $70.11 \pm 11.91$ beats/min, group L 72.74 \pm 9.03 beats $/ \mathrm{min}$ ) declined relative to rates before labetalol injection (group S $72.96 \pm 12.32$ beats/min, group L $78.78 \pm$

Table 1. Demographic Data

\begin{tabular}{lcc}
\hline & Group S (n=27) & Group L $(\mathrm{n}=27)$ \\
\hline Age (yr) & $41.26 \pm 10.45$ & $41.89 \pm 9.71$ \\
Sex (M/F) & $6 / 21$ & $5 / 22$ \\
Height (cm) & $159.07 \pm 9.19$ & $161.67 \pm 7.96$ \\
Weight (kg) & $58.38 \pm 9.47$ & $61.90 \pm 9.05$
\end{tabular}

Values are expressed as mean \pm SD or number of patients. Group S: normal saline, Group L: labetalol $0.3 \mathrm{mg} / \mathrm{kg}$.

A

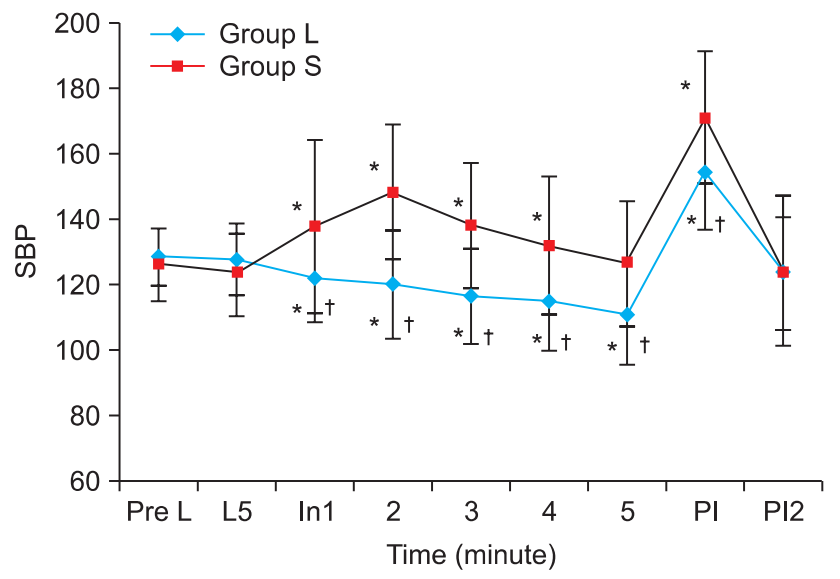

C

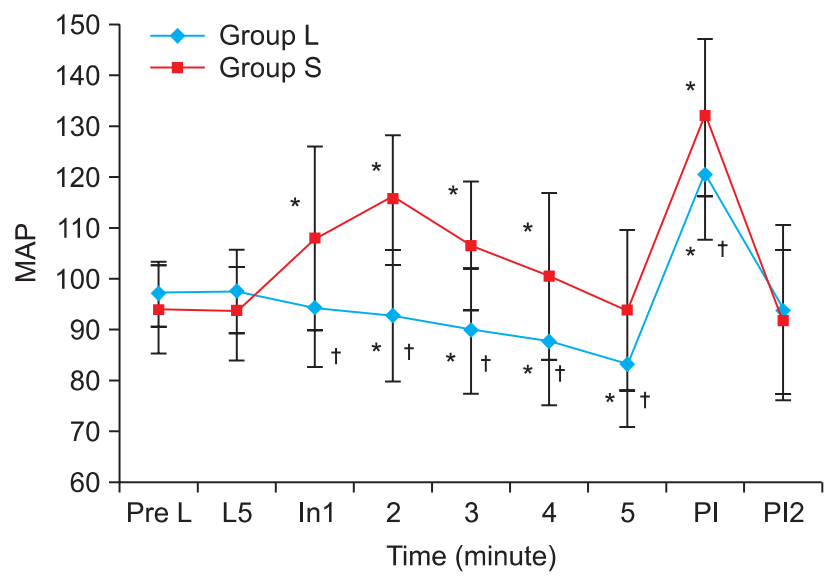

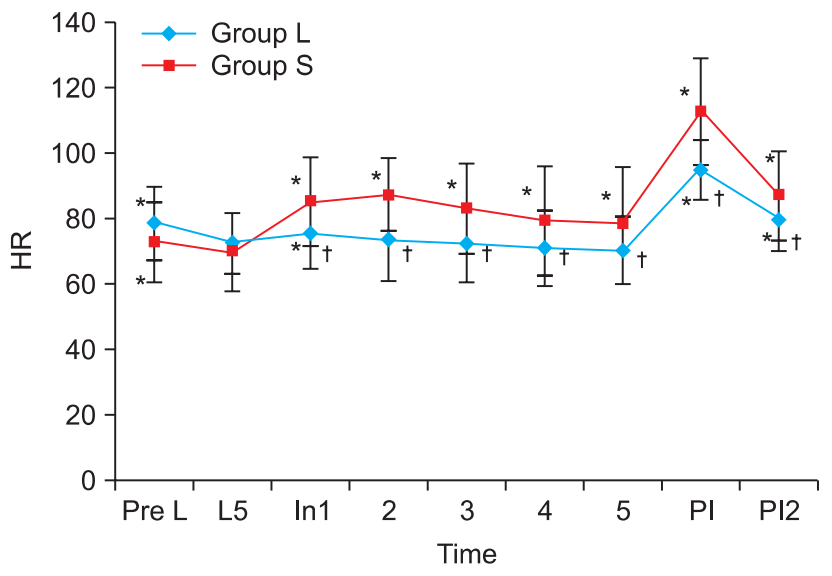

Fig. 1. Changes in heart rate. Group L: labetalol $0.3 \mathrm{mg} / \mathrm{kg}$, Group S: normal saline. Pre L: just before intravenous injection of labetalol or normal saline. L5: baseline and $5 \mathrm{~min}$ after intravenous injection of labetalol or normal saline, just before desflurane inhalation. At 1, 2, 3, 4, 5: 1, 2, 3, 4, 5 min after desflurane inhalation. PI, PI2: immediately, 2 min after intubation. $* \mathrm{P}<0.05$ compared with baseline value (L5) within the group. ${ }^{\dagger} \mathrm{P}<0.05$ compared with the corresponding values of group S.

B

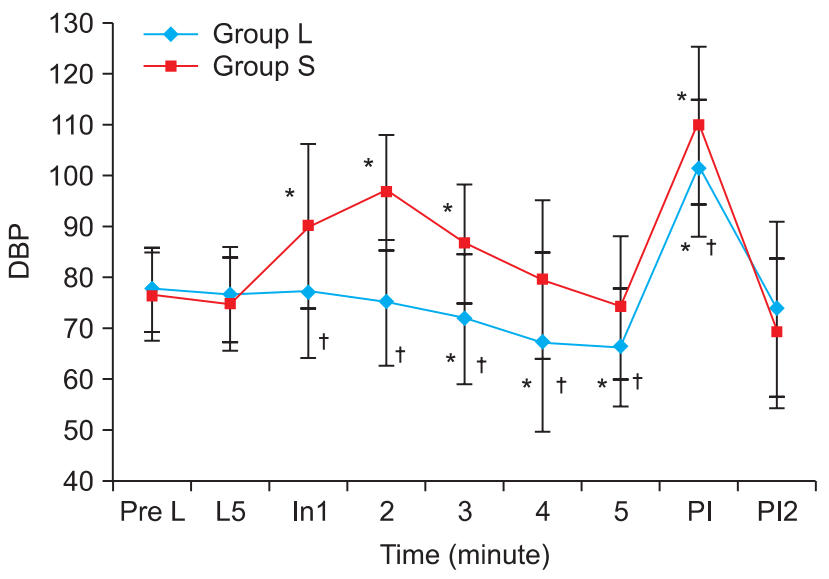

Fig. 2. Changes in systolic (A) and diastolic blood pressure (B) and mean arterial pressure (C). Group L: labetalol $0.3 \mathrm{mg} / \mathrm{kg}$, Group S: normal saline. Pre L: just before intravenous injection of labetalol or normal saline. L5: baseline and $5 \mathrm{~min}$ after intravenous injection of labetalol or normal saline, just before desflurane inhalation. At 1, 2, 3, 4, 5: 1, 2, 3, 4, 5 min after desflurane inhalation. PI, PI2: immediately, 2 min after intubation. ${ }^{*} \mathrm{P}<0.05$ compared with baseline value (L5) within the group. ${ }^{\dagger} \mathrm{P}<0.05$ compared with the corresponding values of group S. 


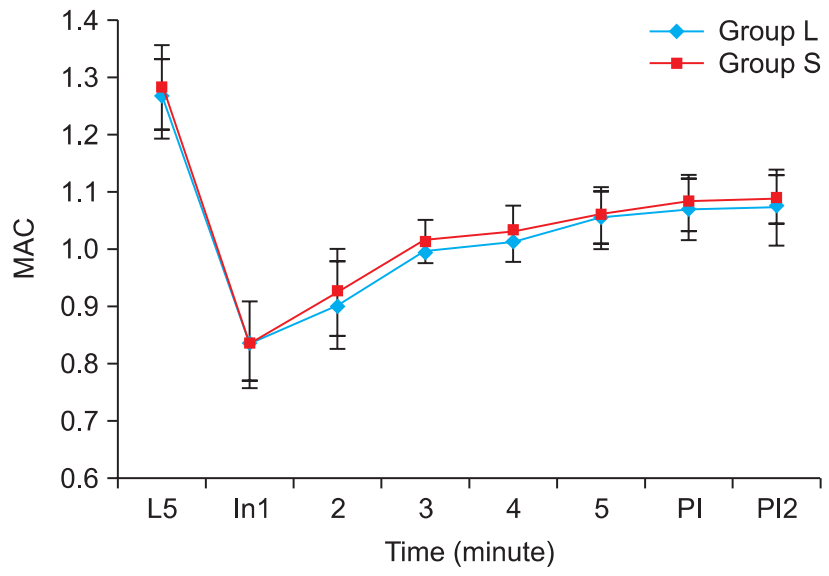

Fig. 3. Changes in end-tidal concentration of desflurane (MAC). There are no significant differences between the 2 groups. Group L: labetalol $0.3 \mathrm{mg} / \mathrm{kg}$, Group S: normal saline. L5: $5 \mathrm{~min}$ after intravenous injection of labetalol or normal saline, just before desflurane inhalation. At 1, 2, 3, 4, 5: 1, 2, 3, 4, 5 min after desflurane inhalation. PI, PI2: immediately, 2 min after intubation.

11.24 beats $/ \mathrm{min}$ ) in both groups $(\mathrm{P}<0.05)$, but $\mathrm{BP}$ did not show a significant change (Fig. 1 and 2). There were no significant differences in the HR and BP between two groups at that time (Fig. 1 and 2).

The end tidal desflurane concentrations in the primed anesthesia circuit before induction of anesthesia were $1.28 \pm$ 0.07 MAC in group S and 1.26 \pm 0.07 MAC in group L. There were no significant differences between the groups. The end tidal concentration at 1 minute after desflurane inhalation was $0.83 \pm 0.07$ in group S and 0.84 $\pm 0.07 \mathrm{MAC}$, and reached $1 \mathrm{MAC}$ within 3 minutes in both groups. End tidal concentration was calculated as $1.09 \pm 0.04 \mathrm{MAC}$ in group $\mathrm{S}$ and $1.07 \pm 0.07 \mathrm{MAC}$ in group $\mathrm{L}$ at 2 minutes after endotracheal intubation, and there were no noticeable differences between the degrees of increasing end tidal concentration with increasing time (Fig. 3).

After desflurane inhalation ranging 1 to 5 minutes, HR had significantly increased as compared to baseline, and peaked in 2 minutes in group $S(P<0.05)$ (Fig. 1). In group L, HR significantly increased as compared to baseline after desflurane inhalation after 1 minute $(\mathrm{P}<0.05)$ (Fig. 1). Group $\mathrm{S}$ had higher values than group $\mathrm{L}$ when comparing the degree of increasing heart rate resulting from desflurane inhalation $(\mathrm{P}<0.05)$ (Fig. 1). HR increased significantly when compared with baseline in both groups after intubation, but the increasing rates of group $S$ were greater than those in group $\mathrm{L}(\mathrm{P}<0.05)$ (Fig. 1).

Systolic and diastolic blood pressure increased significantly after desflurane inhalation and reached a peak within 2 minutes in group $\mathrm{S}$, but then decreased after 2 minutes $(\mathrm{P}<0.05)$ (Fig. 2). In group $\mathrm{L}$, the $\mathrm{BP}$ decreased after desflurane inhalation and had significantly low values as compared baseline from
Table 2. Incidence of the Side Effects

\begin{tabular}{llcc}
\hline & & Group S $(\mathrm{n}=27)$ & Group L $(\mathrm{n}=27)$ \\
\hline \multirow{2}{*}{ Hypertension } & Preintubation & 3 & 0 \\
& Postintubation & 10 & $0^{*}$ \\
Tachycardia & Preintubation & 0 & 0 \\
& Postintubation & 3 & 0
\end{tabular}

Values are number of patients. Hypertension: $\geq 180 \mathrm{mmHg}$ of systolic blood pressure. Tachycardia: $\geq 130$ beats/min. Group S: normal saline, Group L: labetalol $0.3 \mathrm{mg} / \mathrm{kg}$. ${ }^{*} \mathrm{P}<0.05$ compared with group $\mathrm{S}$.

three to five minutes after desflurane inhalation $(\mathrm{P}<0.01)$ (Fig. 2). Group $S$ had been greater than group $L$ in the increasing degree of systolic and diastolic blood pressure according to desflurane inhalation $(\mathrm{P}<0.01)$ (Fig. 2). Systolic and diastolic blood pressure immediately after endotracheal intubation increased significantly as compared to baseline, but the degrees of increase in group $\mathrm{S}$ were much higher than in group $\mathrm{L}(\mathrm{P}<$ 0.05) (Fig. 2).

Mean arterial pressure (MAP) increased significantly from 1 to 4 minutes after desflurane and reached peaks at 2 minutes in group $\mathrm{S}(\mathrm{P}<0.05)$ (Fig. 2). In group L, MAP was lower than baseline from 2 to 5 minutes after desflurane inhalation $(\mathrm{P}<$ 0.05) (Fig. 2). MAP increased immediately after intubation $(\mathrm{P}<$ 0.01 ) (Fig. 2). The degree of increase in group $S$ was higher than in group $\mathrm{L}$ according to desflurane inhalation $(\mathrm{P}<0.01$ ) (Fig. 2).

Three subjects had severe hypertension in group $\mathrm{S}$ after desflurane inhalation through a facial mask, but there were no statistical differences between group S and group L (Table 2). After endotracheal intubation 10 subjects had severe hypertension in group $\mathrm{S}$, and there was a noticeable difference when comparing the 2 groups (Table 2). However, there was no difference in frequency of severe tachycardia (3 subjects in group S, none in group L) (Table 2). In addition, there were no side effects of hypotension $(\leq 80 \mathrm{mmHg}$ of systolic BP or decreasing $30 \%$ more than baseline in MAP), bradyrhythmia ( $\leq 45$ beats/min), arrhythmia, laryngospasm or bronchospasm.

\section{Discussion}

In this study, patients in the saline injection group showed the same pattern as those in previous studies where blood pressure and heart rate temporarily increased after desflurane inhalation and then gradually decreased $[3,6,7]$. Although it is uncommon that hemodynamic responses produced by desflurane are actually harmful to patients, there are studies documenting the occurrence of severe tachycardia (HR $>160$ beats/min) or hypertension (systolic $\mathrm{BP}>200 \mathrm{mmHg}$ ) during induction of anesthesia $[3,6,7]$. We also found a case of severe systolic hypertension ( $>180 \mathrm{mmHg}$ ). In addition, it could be that desflurane inhalation temporarily increased the blood 
pressure and heart rate, but no case has been reported where desflurane inhalation caused myocardial ischemia in patients who had coronary artery disease [2].

Studies have not revealed the mechanism of hemodynamic response to desflurane, but it is considered that temporal activation of the sympathetic nervous system may be a main cause [8]. Diverse methods including medications (fentanyl, esmolol and lidocaine), and controlling of the rate of increase in inhaled desflurane concentration have been used to reduce these hemodynamic responses $[1,3,4]$. Opioids such as fentanyl effectively controlled hypertension and tachycardia caused by inhalation of desflurane [1]. In contrast, esmolol and lidocaine, and slow increases in desflurane concentration were effective to attenuate increase of $\mathrm{HR}$, but not increase of BP $[1,3,4]$. In this study, HR was increased temporally at 1 minute after desflurane inhalation in the labetalol group but the range of increase was less than in the saline group. In addition, it showed that BP after desflurane inhalation lower than baseline. Although there were increases of $\mathrm{HR}$ and BP immediately after desflurane inhalation in a fentanyl $(4.5 \mu \mathrm{g} / \mathrm{kg})$ pre-injection study, Weiskopf et al. [1] suggested that fentanyl could effectively control the hemodynamic response to desflurane. Therefore, labetalol may have been effective in controlling hemodynamic response to desflurane. This result presumes that labetalol, a combined blocker of $\alpha_{1}, \beta$-receptor, attenuated hypertension and tachycardia resulting from an increase of systemic vascular resistance and blood catecholamine by desflurane inhalation [8].

Endotracheal intubation would cause excessive hypertension and tachycardia due to an activation of the sympathetic nervous system. Desflurane-administrated for anesthesia sharply increased the level of blood catecholamine and this effect was also related to activation of the sympathetic nervous system. Normalization of these effects can require more than 10 minutes [8]. Therefore, it is possible that desflurane intensifies cardiovascular reaction to endotracheal intubation during induction of anesthesia. In this study, we induced anesthesia and started desflurane inhalation 5 minutes after injecting of labetalol, and then endotracheal intubation was performed 10 minutes after labetalol injection. This was because we intended to effectively control hemodynamic changes produced by desflurane and endotracheal intubation based on the fact that the hypotensive effect of labetalol begins 2-5 minustes after injection and shows a maximum effect at 5 to 15 minutes $[5,9]$. As a result, even though heart rate and blood pressure had risen as compared to baseline values after endotracheal intubation in the labetalol group, the level of increase was meaningfully lower than in the saline group. In addition, severe hypertension and tachycardia occurred in 10 and 3 patients, respectively in the saline group, but these effects did not occur in the labetalol group. Consequently, labetalol preinjection is thought to be a useful method to control hemodynamic responses to not only desflurane inhalation but also to endotracheal intubation.

The increases of HR and BP produced by desflurane were temporary, and were reduced as the time of pretreatment passed 5 minutes [8]. Therefore, severe hypotension and bradycardia could occur when using labetalol, having long duration of action [5,9], to block cardiovascular stimulation of desflurane. Especially, these risks would have been higher from the start of endotracheal intubation to initiating the operation because of a lack of stimulation. However, excessive hypotension and bradycardia did not occur in this study. This could be because the sympathetic nervous system activation by desflurane and the use of etomidate produced lower cardiovascular inhibition than other anesthetic inducers for anesthesia induction. Labetalol was also rapidly redistributed in the body (distribution half-life $5.9 \mathrm{~min}$ ) and levels in the blood were abruptly reduced [5]. It was reported that mean labetalol level $\geq 300 \mathrm{mg}$ are required to maintain mean arterial pressure at $60 \mathrm{mmHg}$ when middle ear surgery was performed during 80 minutes under induced hypotension for a normotensive patient [10]. In contrast, in this study, labetalol $(0.3 \mathrm{mg} / \mathrm{kg})$ was only used at a dose of $20 \mathrm{mg}$ for a normal adult (weight $60-70 \mathrm{~kg}$ ), and did not cause an excessive hypotension and bradycardia. According to the literature, an injection of labetalol $(0.25 \mathrm{mg} /$ $\mathrm{kg}$ ) to block cardiovascular reaction during endotracheal intubation, produced no hypotension and bradycardia during 10 minutes after intubation, while maintaining anesthesia with propofol [11]. Also, it was reported that BP decreased only $17 \%$ after a labetalol injection of $1.5 \mathrm{mg} / \mathrm{kg}$ [5]. The effect of labetalol continues during an operation or after a recovery from anesthesia. It is rare for these side effects to occur because labetalol has an ability to rapidly redistribute in the body and the sympathetic nervous system is activated by pain related to an operation. Indeed, in a study of a $20 \mathrm{mg}$ labetalol injection in to patients undergoing maxillofacial surgery, hypotension and bradycardia did not occur during or after the operation [12]. It is thought that the occurrence of severe hypotension and bradycardia is rare even though labetalol is used to control cardiovascular reaction produced by desflurane.

Desflurane is not commonly used for pediatric anesthesia and patients with respiratory illness such as asthma because of a pungent effect on the airway and no bronchodilating effect, unlike other inhaled anesthetics [13]. The possibility should be considered that simultaneous administration of desflurane and a $\beta$-adrenergic receptor blocker causes bronchospasm because a $\beta$-adrenergic receptor blocker such as labetalol can attenuate bronchodilation. Common side effects of desflurane are cough, breath holding, and laryngospasm [14], but it is rare that bronchospasm by desflurane occurs in normal adults without a respiratory problem. Moreover, it is reported that 
labetalol, unlike other $\beta$-adrenergic receptors blockers, has little impact on the respiratory tract $[15,16]$. In practice, some studies reported that labetalol can be used to treat hypertension patients having asthma or chronic bronchitis without respiratory side effects $[17,18]$. Therefore, it is considered unlikely that the use of labetalol during desflurane inhalation will result in bronchospasm in normal healthy adults.

Labetalol is initially injected at a dose of $20 \mathrm{mg}$ and injection are repeated every 10 minutes according to change of vital signs in patients [9]. The labetalol injection dose of $20 \mathrm{mg}$ (in case of a normal adult) was only the first time dose investigated in this study; however any hemodynamic reaction to desflurane was effectively controlled. Therefore, we did not use a higher dose of labetalol because the current dose of labetalol was sufficient to control a hemodynamic response to desflurane and severe hypotension could occur if the dose was increased. Studies should be conducted to investigate whether a lower dose of labetalol can effectively control cardiovascular reaction induced by desflurane because it cannot be excluded that a labetalol dose of $0.3 \mathrm{mg} / \mathrm{kg}$ causes bronchodilatory inhibition, bradycardia, and hypotension.

In conclusion, BP and HR were rapidly increased in response to a $\geq 1$ MAC in desflurane concentration, but hemodynamic response of desflurane inhalation could be effectively suppressed by administration of $0.3 \mathrm{mg} / \mathrm{kg}$ labetalol. Furthermore, we believe that to some extent, increases of BP and HR by endotracheal intubation can be attenuated by labetalol.

\section{References}

1. Weiskopf RB, Eger EI 2nd, Noorani M, Daniel M. Fentanyl, esmolol, and clonidine blunt the transient cardiovascular stimulation induced by desflurane in humans. Anesthesiology 1994; 81: 1350-5.

2. Helman JD, Leung JM, Bellows WH, Pineda N, Roach GW, Reeves JD 3rd, et al. The risk of myocardial ischemia in patients receiving desflurane versus sufentanil anesthesia for coronary artery bypass graft surgery. Anesthesiology 1992; 77: 47-62.

3. Kim EA, Lee SS, Lim HS, Ko SH, Lee JR, Lee SK, et al. Comparison of desflurane-induced circulatory responses by the rate of increase in inhaled desflurane concentration. Korean J Anesthesiol 2005; 49: 466-71.

4. Gormley WP, Murray JM, Trinick TR. Intravenous lidocaine does not attenuate the cardiovascular and catecholamine response to a rapid increase in desflurane concentration. Anesth Analg 1996; 82: $358-61$.

5. Kanto J, Allonen H, Kleimola T, Mäntylä R. Pharmacokinetics of labetalol in healthy volunteers. Int J Clin Pharmacol Ther Toxicol 1981; 19: 41-4.

6. Kim D, Kim EA, Seo MJ, Lim H, Ko S, Lee SK. Desflurane-induced hemodynamic changes in patients with diabetic cardiovascular autonomic neuropathy. Korean J Anesthesiol 2009; 57: 560-5.

7. Kim EA, Lee JW, Lim HS, Son JS, Ko SH. Desflurane-induced hemodynamic changes in patients with hypertension. Korean J Anesthesiol 2007; 52: 516-20.

8. Weiskopf RB, Moore MA, Eger EI 2nd, Noorani M, McKay L, Chortkoff B, et al. Rapid increase in desflurane concentration is associated with greater transient cardiovascular stimulation than with rapid increase in isoflurane concentration in humans. Anesthesiology 1994; 80: 1035-45.

9. Varon J, Marik PE. The diagnosis and management of hypertensive crises. Chest 2000; 118: 214-27.

10. Matson AM, Shaw M, Loughnan BA, Burrin JM, Hall GM. Pituitaryadrenal, hormonal changes during induced hypotension with labetol or isoflurane for middle-ear surgery. Acta Anaesthesiol Scand 1998; 42: 17-22.

11. Singh SP, Quadir A, Malhotra P. Comparison of esmolol and labetalol, in low doses, for attenuation of sympathomimetic response to laryngoscopy and intubation. Saudi J Anaesth 2010; 4: 163-8.

12. Lee JR. Effects of induced hypotension with labetalol on blood loss and blood pressure in maxillofacial surgical patients. Korean J Anesthesiol 1998; 34: 1009-13.

13. Goff MJ, Arain SR, Ficke DJ, Uhrich TD, Ebert TJ. Absence of bronchodilation during desflurane anesthesia: a comparison to sevoflurane and thiopental. Anesthesiology 2000; 93: 404-8.

14. Ebert TJ, Schmid PG. Inhaled anesthetics. In: Clinical anesthesia. 6th ed. Edited by Barash PG: Philadelphia, Lippincott Williams \& Wilkins. 2009, p 423.

15. Maconochie JG, Woodings EP, Richards DA. Effects of labetalol and propranolol on histamine-induced bronchoconstriction in normal subjects. Br J Clin Pharmacol 1977; 4: 157-62.

16. Clerici C, Harf A, Macquin-Mavier I. Failure of enhancement by labetalol of bronchopulmonary effects of histamine in guinea-pigs: independence of alpha-adrenoceptor antagonism. Br J Pharmacol 1987; 91: 487-92.

17. Adam WR, Meagher EJ, Barter CE. Labetalol, beta blockers, and acute deterioration of chronic airway obstruction. Clin Exp Hypertens A 1982; 4: 1419-28.

18. George RB, Light RW, Hudson L, Conrad SA, Manocha KL, Burford JG. The use of labetalol for the treatment of hypertension in patients with reversible airway obstruction. J Clin Hypertens 1985; 1: 80-3. 